\title{
In Vivo Inflammatory Activity of Epidermal Cell-derived Thymocyte Activating Factor and Recombinant Interleukin 1 in the Mouse
}

Richard D. Granstein, Randall Margolis, Steven B. Mizel, and Daniel N. Sauder

Department of Dermatology, Harvard Medical School and Massachusetts General Hospital, Boston, Massachusetts 02114; Microbiology Program, Pennsylvania State University, University Park, Pennsylvania 16802; and Division of Dermatology, McMaster University, Hamilton, Ontario, L8N 3Z5, Canada

\begin{abstract}
Epidermal cell-derived thymocyte activating factor (ETAF), a cytokine produced by keratinocytes, has previously been shown to be biochemically and functionally very similar, if not identical, to interleukin 1 (IL-1). Both ETAF and IL-1 have been demonstrated to be chemotactic for neutrophils and mononuclear cells in vitro. In order to demonstrate that this activity has physiological relevance we have used a simple in vivo model. The present study demonstrates that injection of high-titer ETAF or purified recombinant murine $\mathrm{IL-1}$ into the mouse footpad results in an influx of neutrophils into the site with peak accumulation at $4 \mathrm{~h}$. Footpad swelling also occurs with a time course roughly paralleling that of the neutrophil accumulation. Injection of control proteins failed to reproduce this phenomenon. Margination of neutrophils within blood vessels was seen within $1 \mathrm{~h}$ of injection of ETAF or IL-1, followed by entry into the stroma by $4 \mathrm{~h}$. This suggests that chemotactic activity and not merely increased adherence or inhibition of migration is occurring. 5-10 d of daily, subcutaneous injection of ETAF on the mouse flank resulted in an infiltrate of neutrophils, and to a lesser degree, mononuclear cells in association with epidermal hyperplasia, subcutaneous fibrosis, and focal muscle necrosis in the panniculus carnosus. These findings were not seen in control sites injected with media. These findings provide direct in vivo experimental evidence suggesting a physiologic role for ETAF/IL-1 in local inflammation.
\end{abstract}

\section{Introduction}

The role of antigen-nonspecific cytokines in regulation of various aspects of immunity has received considerable attention. One of these cytokines, interleukin 1 (IL-1), ${ }^{1}$ has been extensively studied and has been found to have a number of important hormone-like activities. The activities of IL-1 (or perhaps the IL-1 set of molecules) include augmentation of the mitogenic response of thymocytes and thymocyte helper function $(1,2)$,

Address reprint requests to Dr. Granstein, Department of Dermatology, Massachusetts General Hospital, Wellman-2, Boston, MA 02114.

Dr. Mizel's current address is Dept. of Microbiology and Immunology, Bowman Gray School of Medicine, Wake Forest University, WinstonSalem, North Carolina 27103.

Received for publication 17 June 1985 and in revised form 24 October 1985.

1. Abbreviations used in this paper: ETAF, epidermal cell-derived thymocyte activating factor; HPLC, high performance liquid chromatography; IL-1, interleukin 1.

J. Clin. Invest.

(c) The American Society for Clinical Investigation, Inc.

$0021-9738 / 86 / 03 / 1020 / 08 \$ 1.00$

Volume 77, March 1986, 1020-1027 induction of interleukin 2 receptors on $T$ cells (3), augmentation of natural killer-cell activity (4), involvement in B cell proliferation and antibody production $(5,6)$, endogenous pyrogen activity $(7,8)$, involvement in lactoferrin release from neutrophils (9), involvement in the production of acute phase proteins (10, 11 ), induction of protein degradation and prostaglandin $E_{2}$ production in muscle (12), activation of fibroblasts (13), and induction of slow-wave sleep (14). IL-1 was originally described as a monocyte-derived growth factor; however, a factor is made by keratinocytes, termed epidermal cell-derived thymocyte activating factor (ETAF), which is biologically and biochemically very similar or identical to IL-1 (15-18). Recently, in vitro studies have demonstrated both IL-1 and ETAF to be chemotactic for neutrophils and mononuclear cells (19-21). These various properties suggest, of course, that IL-1/ETAF plays an important in vivo role in inflammatory processes. We now present evidence that IL-1 and ETAF do indeed have inflammatory properties in vivo that may play an important role in localized inflammation in skin.

\section{Methods}

Mice. Female mice of the inbred strains $\mathrm{C} 3 \mathrm{H} / \mathrm{HeJ}$ and $\mathrm{A} / \mathrm{J}$ were obtained from the Jackson Laboratory (Bar Harbor, ME). The animals were 814 wk old at the start of each experiment and within each experiment the age of the animals did not vary by more than 2 wk. The mice had free access to Purina Mouse Chow (Ralston Purina Co., St. Louis, MO) and chlorinated water and were housed in a facility where ambient light was regulated on a 12-h light/dark cycle.

Preparation of ETAF. ETAF was prepared from normal human epidermal cells as previously described (16). Briefly, human epidermal cells were obtained from keratomed sections of whole skin by treatment with trypsin and cultured in Dulbecco's modified Eagle's medium containing $5 \%$ fetal calf serum without any additional stimulants. Medium (crude ETAF) was collected after $5 \mathrm{~d}$. Crude ETAF was dialyzed for $24 \mathrm{~h}$ against phosphate-buffered saline (PBS) in order to remove low molecular weight inhibitory activities. To obtain ETAF with higher specific activity, crude ETAF was first subjected to ultrafiltration using an ultrafiltration unit equipped with a YM-50 filter (Amicon Corp., Danvers, MA). The filtrate (less than $50,000 \mathrm{~mol} \mathrm{wt}$ ) was then concentrated 20 -fold by ultrafiltration using an Amicon ultrafiltration unit equipped with a YM-10 filter. The concentrate was then passed over a Sephadex G-100 column (Pharmacia Fine Chemicals, Piscataway, NJ) using PBS as eluant. The fractions eluted from the column in the region corresponding to molecular weights between 12,000 and 18,000 (mean 15,000 mol wt) were pooled and filtered through a $0.45 \mu \mathrm{m}$ Millipore filter (Waters Associates, Millipore Corp., Milford, MA) and chromatographed on a $41 \times 250 \mathrm{~nm}$ Synchropak AX 300 ion exchange column (Synchrom, Inc., Linden, IN) using a Gilson high performance liquid chromatography (HPLC) system (Gilson France S.A., Villiers le Bel, France). Starting buffer was $20 \mathrm{mM}$ Tris- $\mathrm{HCl}$ at $\mathrm{pH}$ 7.6 and the gradient buffer was starting buffer augmented with $1 \mathrm{M}$ $\mathrm{NaCl}$. 1-ml fractions were collected, dialyzed against PBS, and assayed in the costimulator assay (22). Active fractions were then pooled and run on a Bio-Sil TSK-250 column (Bio-Rad Laboratories, Rockville Center, NY) using the above Gilson HPLC system. The active fraction 


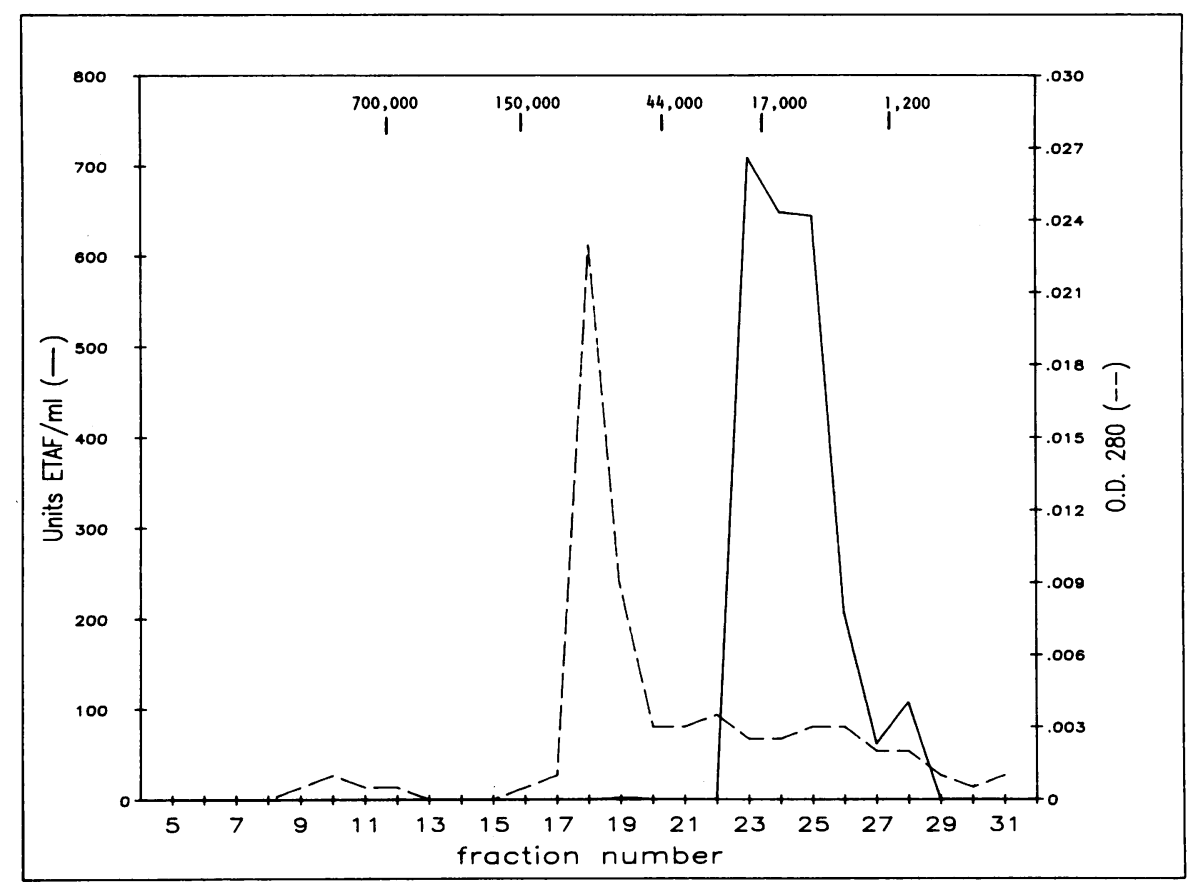

Figure 1. HPLC of purified human ETAF elution was carried out with PBS at a flow rate of $1 \mathrm{ml} / \mathrm{min}$. ETAF activity $(\longrightarrow$ ) was eluted within a molecular weight range of $10,000-20,000$. The major protein peak was seen at a molecular weight of $\sim 68,000$ $(-\cdots-$.$) .$ corresponded to molecular weights between 10,000 and 20,000 (Fig. 1). These fractions were pooled and yielded a concentration of $2 \mu \mathrm{g} / \mathrm{ml}$ of protein. ETAF activity in units per milliliter was determined for these pooled fractions as previously described (22). In some experiments pooled fractions of mean molecular weights of 5,000 and 30,000 were used as controls.

Preparation of $I L-1$. Recombinant IL-1 was prepared and purified as previously described (23). The purified recombinant IL-1 exhibited a specific activity of $\sim 6 \times 10^{6} \mathrm{U} / \mathrm{mg}, 1 \mathrm{U} / \mathrm{ml}$ producing $50 \%$ of the maximal response in the thymocyte costimulator assay (24).

Controls. Solutions of human serum albumin (Sigma Chemical Co. St. Louis, MO), cytochrome $c$ (Sigma Chemical Co.), polyhydroxyproline (Sigma Chemical Co.), and Escherichia coli lipopolysaccharide (Sigma Chemical Co.) were prepared in RPMI 1640 medium. Activated serum was prepared by boiling Zymosan A (Sigma Chemical Co.) in normal saline for 15 min, washing it twice with normal saline, and then adding

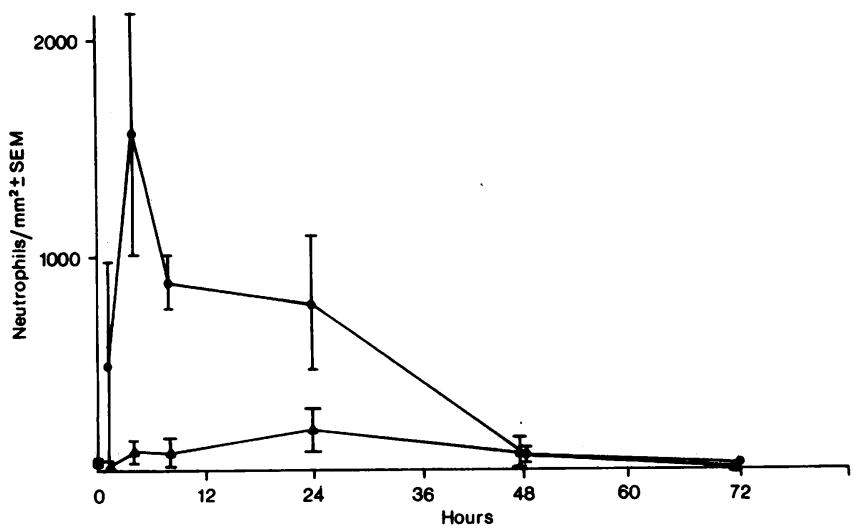

Figure 2. $\mathrm{C} 3 \mathrm{H} / \mathrm{HeJ}$ mice were injected with $0.05 \mathrm{ml}$ of medium containing ETAF in the left hind footpad and medium alone in the right hind footpad. Groups of three mice each were killed at the times indicated. Histologic sections were prepared and neutrophils in the dermis and subcutaneous tissue quantified. Significant differences between ETAF $(\bullet)$ and control medium $(\triangle)$ were seen at $4(P<0.038)$ and 8 $(P<0.004)$ h. $n$, neutrophil count in noninjected animals. it to $\mathrm{C} 3 \mathrm{H} / \mathrm{HeJ}$ serum to a concentration of $5 \mathrm{mg} / \mathrm{ml}$. After incubation at $37^{\circ} \mathrm{C}$ for $1 \mathrm{~h}$, centrifugation at $2,000 \mathrm{~g}$ was performed and the supernatant was decanted and used immediately.

Assay. $0.05 \mathrm{ml}$ of medium containing a test substance was injected subcutaneously into the left hind footpad of each mouse. Identical medium not containing the test substance was injected into the right hind footpad. At various time intervals the footpad thicknesses were measured with a spring-loaded micrometer (Fowler Co., Biggswald, England) followed by killing the mice and preparing footpad tissue for light microscopy. In some experiments, a test substance was injected into the left hind footpad while the same preparation was injected into the right hind footpad after undergoing a treatment. Also in some experiments the left

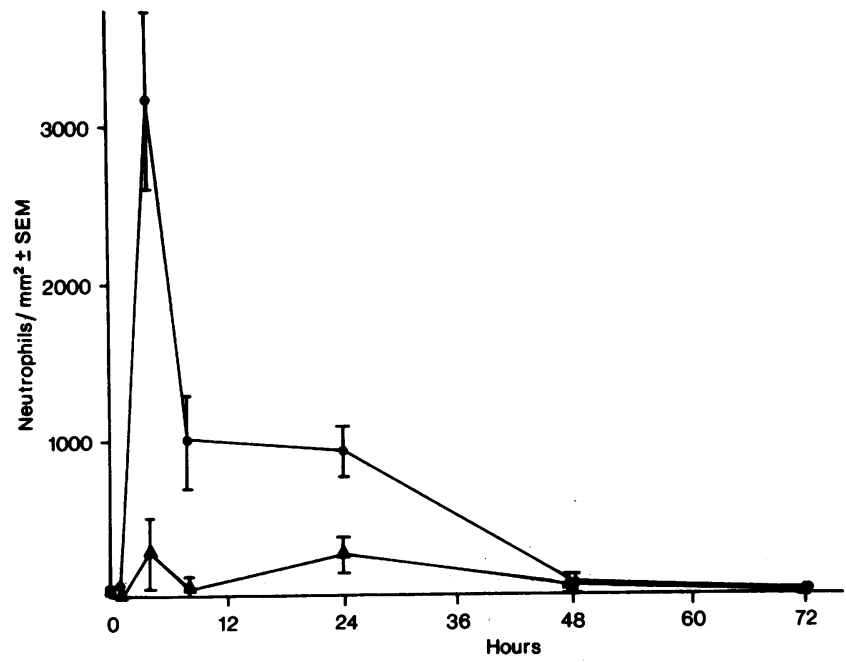

Figure 3. A/J mice were injected with $0.05 \mathrm{ml}$ of medium containing ETAF in the left hind footpad and medium alone in the right hind footpad. Groups of three mice each were killed at the times indicated. Histologic sections were prepared and neutrophils in the dermis and subcutaneous tissue quantified. Significant differences between ETAF (๑) and control medium $(\triangle)$ were seen at $4(P<0.009), 8(P<0.254)$, and $24(P<0.034) h$. $n$, neutrophil count in noninjected animals. 
flank was injected with a test substance daily for 5 to $10 \mathrm{~d}$ while the right flank was injected with the medium control followed by killing the animals and preparing the injected sites for light microscopy.

Endotoxin assay. Endotoxin content of ETAF and recombinant IL1 preparations was assayed by the Limulus amebocyte lysate test (25).

Histology. Tissue was fixed in $10 \%$ buffered formalin and routinely processed. Paraffin-embedded tissue sections were stained with hematoxylin and eosin. Using an ocular grid, $40.14 \mathrm{~mm}^{2}$ cellular areas of each specimen were examined in a coded fashion and inflammatory cells were quantified.

Statistical analysis. The means of different groups were tested by Student's $t$ test.

\section{Results}

Inflammatory activity of ETAF. $0.05 \mathrm{ml}$ of HPLC-purified ETAF in PBS containing $680 \mathrm{U} / \mathrm{ml}$ in the thymocyte proliferation assay was injected into the left hind footpads of mice while medium without ETAF was injected into the right hind footpads. Groups

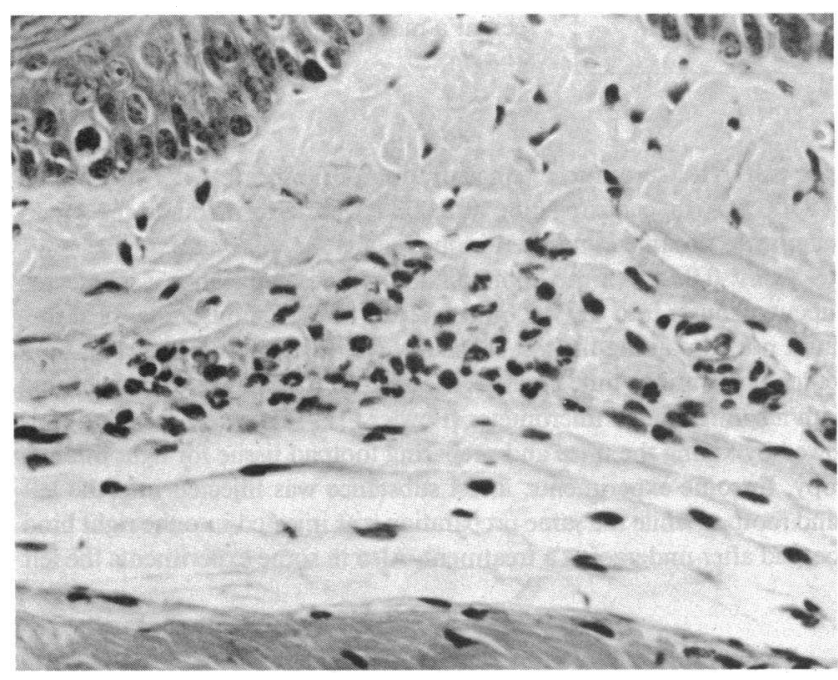

B

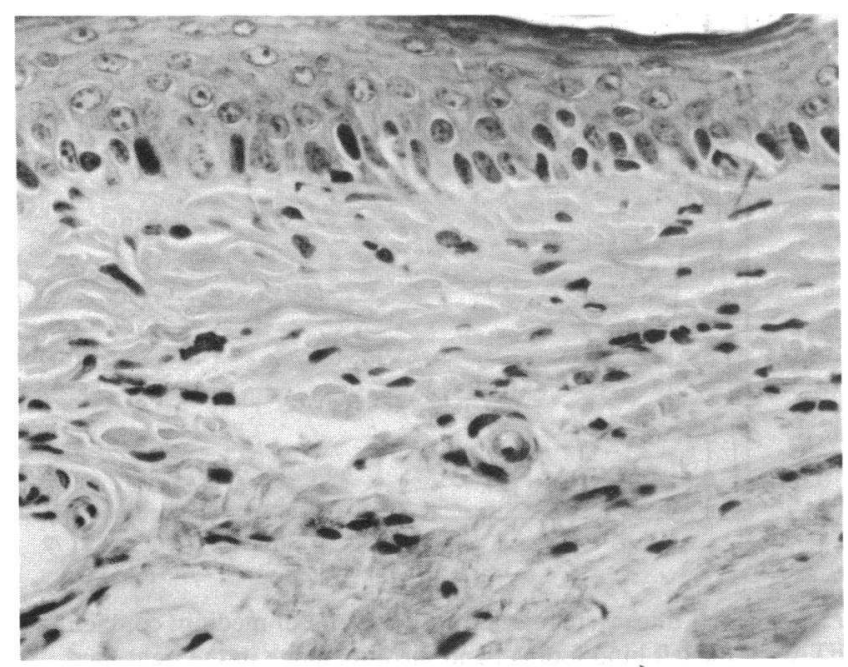

Figure 4. Tissue sections of injected footpads stained with hematoxylin and eosin $4 \mathrm{~h}$ after injection; $\times 500$. $(A)$ ETAF; note dense accumulation of neutrophils. $(B)$ Medium; note only isolated neutrophils present. of mice were killed at various intervals. Footpads were processed for light microscopy, and inflammatory cells infiltrating the dermis and subcutaneous tissue were counted. Fig. 2 shows the results of injecting $\mathrm{C} 3 \mathrm{H} / \mathrm{HeJ}$ mice. ETAF had marked activity in recruiting neutrophils with peak activity at $4 \mathrm{~h}$. Fig. $3 \mathrm{dem}$ onstrates identical findings in $\mathrm{A} / \mathrm{J}$ mice. Footpads injected with medium developed only a small amount of inflammation. Fig. 4 contrasts the findings at $4 \mathrm{~h}$ with $\operatorname{ETAF}(A)$ vs. medium $(B)$. Fig. 5 demonstrates that margination of neutrophils within dermal vessels was apparent as early as $1 \mathrm{~h}$ after injection. This finding, that cells accumulate in vessels followed by exit into the stroma, strongly suggests that chemotactic activity rather than merely increased adherence or inhibition of migration is being observed. No effect on mononuclear cells was seen in this particular experiment. However, some lots of ETAF have demonstrated activity in recruiting mononuclear cells (data not shown). Additional controls shown in Table I demonstrate that pooled HPLC fractions of mean mol wt 5,000 (below the size of the fractions active for thymocyte proliferation) and 30,000 (above the size of the active fractions) have little or no activity in this assay. In addition, column samples taken after medium alone was applied to the column showed no significant activity. Table II demonstrates that heat treatment of ETAF $\left(90^{\circ} \mathrm{C}\right.$ for $15 \mathrm{~min}$ ) substantially, but not completely, diminishes the inflammatory response seen, despite reducing ETAF activity to $<10 \mathrm{U} / \mathrm{ml}$.

Inflammatory activity of IL-1. Purified recombinant IL-1 was also found to have significant recruiting activity for neutrophils in vivo in this assay. $50 \mathrm{U}$ of IL-1 in $0.05 \mathrm{ml}$ of RPMI 1640 medium containing $0.5 \%$ fetal calf serum was injected into the left hind footpad of each mouse, while medium alone was injected into the right hind footpad. Fig. $6(\mathrm{C} 3 \mathrm{H} / \mathrm{HeJ}$ mice $)$ and Fig. 7 (A/J mice) demonstrate that peak activity was seen at 4 h. No effect on mononuclear cells was observed in either strain. Table III demonstrates that heat treatment of IL- $1\left(90^{\circ} \mathrm{C}\right.$ for 15 min) abrogates the chemotactic response.

Endotoxin content of ETAF and IL-1 preparations. The Limulus amebocyte lysate test was employed to determine the endotoxin content of our IL-1 and ETAF preparations. The

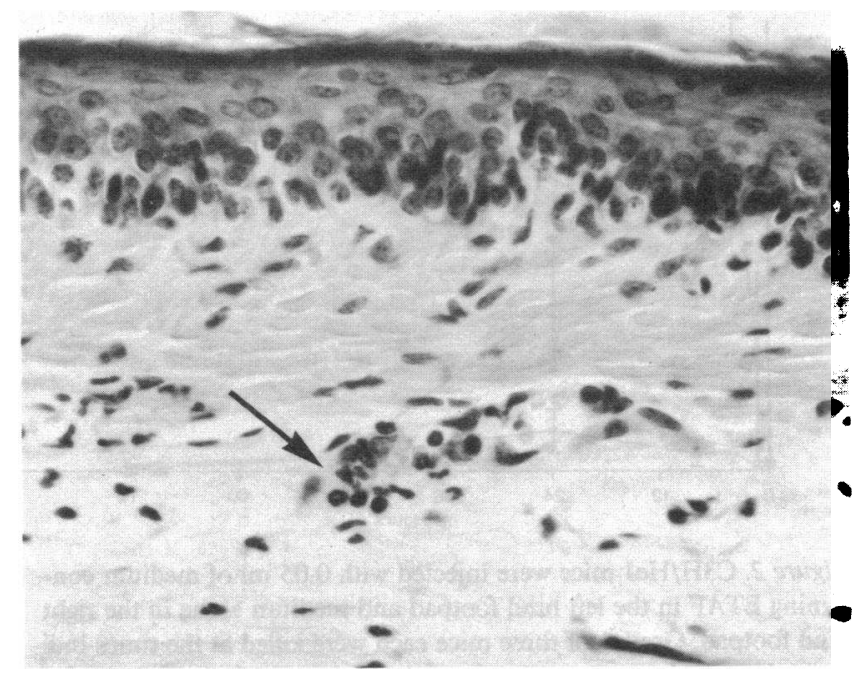

Figure 5. Tissue section, stained with hematoxylin and eosin, of footpad injected with ETAF after $1 \mathrm{~h}, \times 500$. Note margination of neutrophils within vessel (arrow). 
Table I. Inflammatory Activity of TSK-250 Fractions

\begin{tabular}{|c|c|c|}
\hline Injection group* & Neutrophils $/ \mathrm{mm}^{2} \pm$ SEM & $P$ valueł \\
\hline Medium (not put through column) & $28 \pm 18$ & - \\
\hline Pre-ETAF (mean mol wt 5,000) & $61 \pm 3$ & NS \\
\hline ETAF (mean mol wt 15,000 ) & $809 \pm 108$ & $<0.003$ \\
\hline Post-ETAF (mean mol wt 30,000 ) & $74 \pm 15$ & NS \\
\hline Medium (mean mol wt 5,000) & $115 \pm 56$ & NS \\
\hline Medium (mean mol wt 15,000 ) & $140 \pm 36$ & NS \\
\hline Medium (mean mol wt 30,000) & $46 \pm 15$ & NS \\
\hline
\end{tabular}

* Three A/J mice injected with $0.05 \mathrm{ml}$ of medium containing various fractions from the TSK-250 column after application of active material to the column (groups 2-4) or application of medium (groups 57 ) in the left hind footpad. Mice were killed $4 \mathrm{~h}$ after and tissue processed.

$\ddagger$ All groups compared with group 1 .

ETAF preparation contained $<1 \mathrm{ng} / \mathrm{ml}$ of endotoxin, while the IL-1 preparation contained $<2 \mathrm{ng} / \mathrm{ml}$. Table IV demonstrates that even a concentration of $20 \mathrm{ng} / \mathrm{ml}$ is inactive in our assay at $4 \mathrm{~h}$.

Effects of ETAF/IL-1 on footpad swelling. Figs. 8 and 9 demonstrate that both ETAF and IL-1 cause the mouse footpad to swell relative to controls injected with medium. This is true in both $\mathrm{C} 3 \mathrm{H} / \mathrm{HeJ}$ (Figs. $8 A$ and $9 A$ ) and $\mathrm{A} / \mathrm{J}$ mice (Figs. $8 B$ and $9 B$ ). The time course of the swelling with both ETAF and IL-1 is roughly similar to that seen (above) for neutrophil infiltration, with a peak at $\sim 4-8 \mathrm{~h}$.
Table II. Heat Treatment Reduces the Inflammatory Activity of ETAF

\begin{tabular}{|c|c|c|}
\hline Injection group* & Neutrophils $/ \mathrm{mm}^{2} \pm \mathrm{SEM}$ & $P$ value \\
\hline ETAF & $1,384 \pm 54$ & - \\
\hline Heat-treated ETAF $\ddagger$ & $682 \pm 66$ & $<0.002 \S$ \\
\hline Medium & $6 \pm 6$ & \\
\hline
\end{tabular}

* Three $\mathrm{C} 3 \mathrm{H} / \mathrm{HeJ}$ mice were injected with $0.05 \mathrm{ml}$ of medium containing $34 \mathrm{U}$ of ETAF in the left hind footpad while an identical amount of heat-treated ETAF was injected in the right hind footpad. An additional three mice were injected with medium alone. Mice were killed $4 \mathrm{~h}$ later and tissue processed.

$\ddagger 90^{\circ} \mathrm{C}$ for $15 \mathrm{~min}$. After heating, this material had $<10 \mathrm{U} / \mathrm{ml}$ of ETAF activity.

$\S$ Compared with group 1.

Inflammatory activity of other proteins. To examine the specificity of the response observed with ETAF and IL-1, preparations of polyhydroxyproline $(15,000 \mathrm{~mol} \mathrm{wt})$, cytochrome $c$ $(12,400 \mathrm{~mol} \mathrm{wt})$, human serum albumin $(60,000 \mathrm{~mol} \mathrm{wt})$ in Hanks' balanced salt solution and Zymosan A-activated serum were tested in this assay. In these experiments each mouse served as its own control with medium injected in the opposite footpad. Tissue was harvested at $4 \mathrm{~h}$. Table $\mathrm{V}$ demonstrates that of the preparations tested, only activated serum caused a significant neutrophilic infiltrate. The other preparations tested resulted in only a small and statistically insignificant increase in neutrophil count despite a protein content equal to or greater than that of

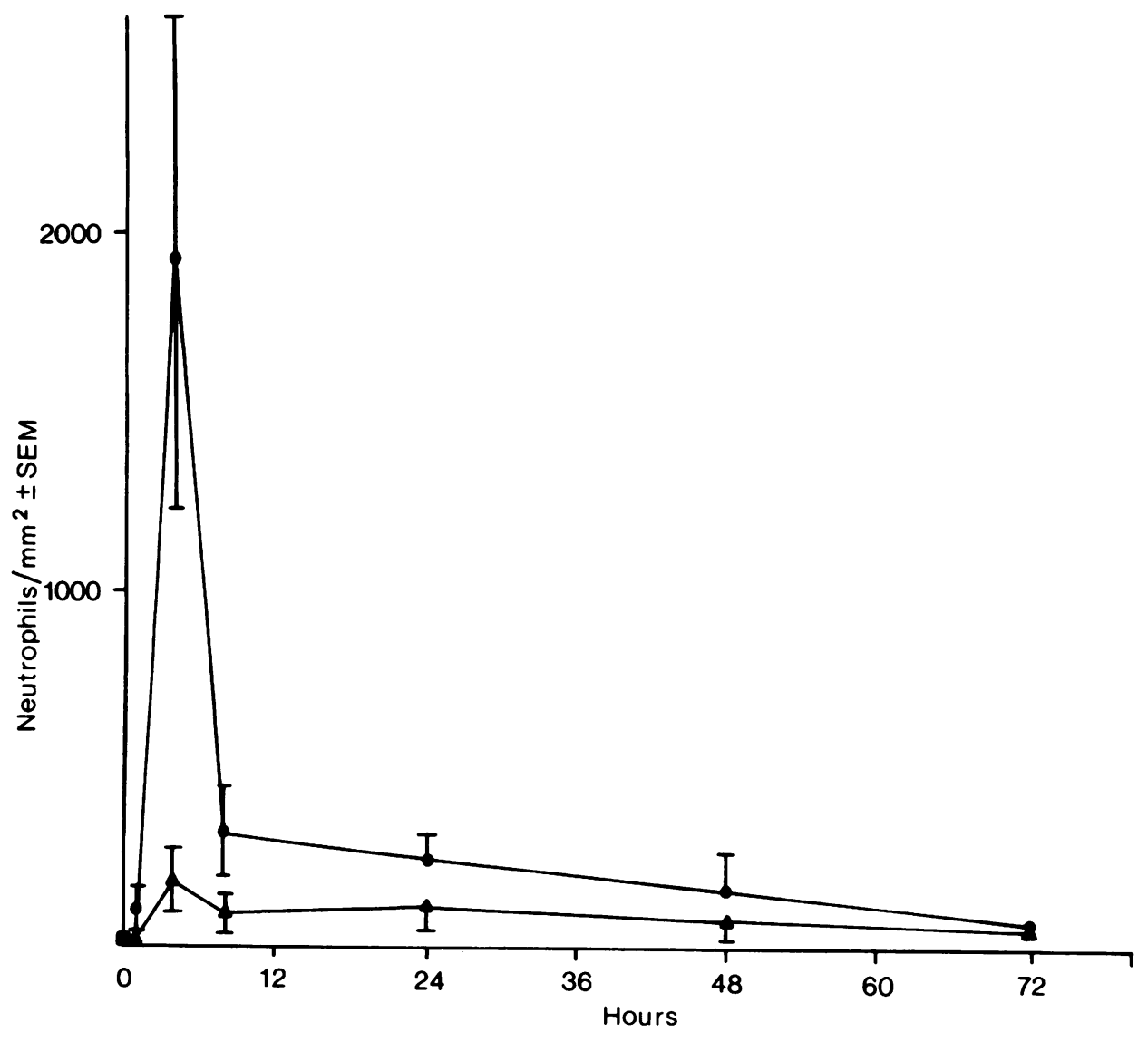

Figure 6. $\mathrm{C} 3 \mathrm{H} / \mathrm{HeJ}$ mice were injected with $0.05 \mathrm{ml}$ of medium containing IL-1 in the left hind footpad and medium alone in the right hind footpad. Groups of three mice each were killed at the times indicated. Histologic sections were prepared and neutrophils in the dermis and subcutaneous tissue quantified. A significant difference between IL-1 $(\bullet)$ and control medium $(\Delta)$ was seen at $4 \mathrm{~h}(P=0.030) . \mathrm{a}$, neutrophil count in noninjected animals. 


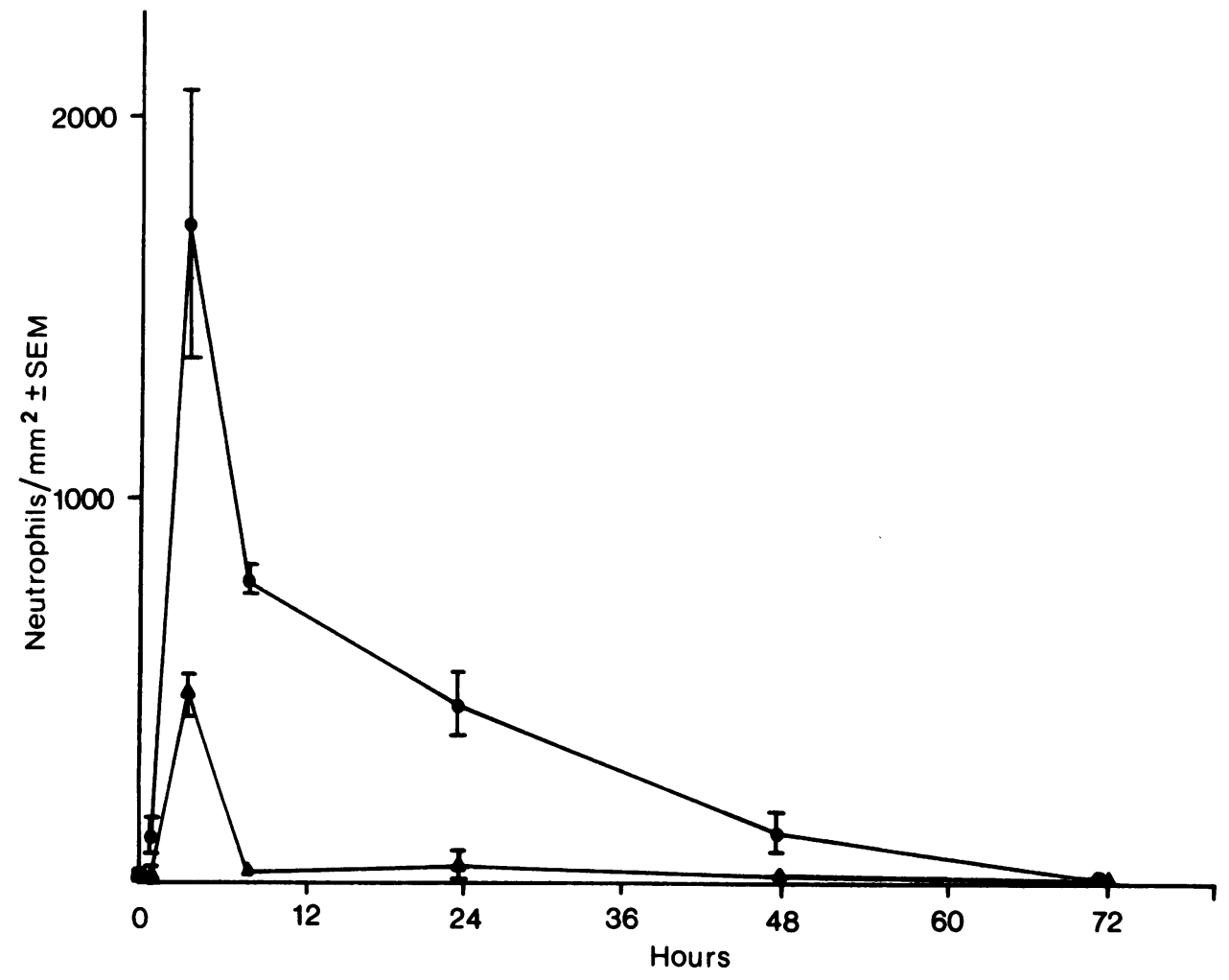

Figure 7. A/J mice were injected with $0.05 \mathrm{ml}$ of medium containing IL-1 in the left hind footpad and medium alone in the right hind footpad. Groups of three mice each were killed at the times indicated. Histologic sections were prepared and neutrophils in the dermis and subcutaneous tissue quantified. Significant differences between IL-1 $(\bullet)$ and control medium $(\Delta)$ were seen at $4 \mathrm{~h}$ $(P=0.031), 8 \mathrm{~h}(P<0.001)$, and 24 $\mathrm{h}(P=0.011) . \mathrm{a}$, neutrophil count in noninjected animals. the ETAF preparation and much greater than that of the purified recombinant IL-1.

Effects of repeated administration of ETAF. $0.05 \mathrm{ml}$ of PBS containing $34 \mathrm{U}$ of purified ETAF was injected subcutaneously on the flanks of two groups of $\mathrm{C} 3 \mathrm{H}$ mice daily at the same site for 5 and $10 \mathrm{~d}$, respectively. Control mice were injected with medium alone. Animals were killed $24 \mathrm{~h}$ after the last injection and the sites of injection processed for light microscopy. At both 5 and $10 \mathrm{~d}$ the following changes were observed in ETAF-injected sites compared with controls, although the changes were more prominent at $10 \mathrm{~d}$ : the epidermis was thickened (four to five cell layers compared with two in the controls), and exhibited maturation disarrangement, as well as scattered mitoses; there was diminished subcutaneous fat with sheets of neutrophils, rare eosinophils, and many mononuclear inflammatory cells in the subcutis and dermis; increased collagen was noted between and about lipocytes; and similar inflammatory cells were seen be-

Table III. Heat Treatment Abrogates

the Inflammatory Activity of IL-I

\begin{tabular}{lcl}
\hline Injection group* & Neutrophils $/ \mathrm{mm}^{2} \pm$ SEM & $P$ value \\
\hline IL-1 & $1,112 \pm 247$ & - \\
Heat-treated IL-1 & $166 \pm 124$ & $<0.027 \S$ \\
Medium & $62 \pm 52$ &
\end{tabular}

* Three $\mathrm{C} 3 \mathrm{H} / \mathrm{HeJ}$ mice were injected with $0.05 \mathrm{ml}$ of medium containing $50 \mathrm{U}$ IL-1 in the left hind footpad while an identical amount of heat-treated IL-1 was injected in the right hind footpad. An additional three mice were injected with medium alone. Mice were killed 4 $h$ later and tissue processed.

$\ddagger 90^{\circ} \mathrm{C}$ for $15 \mathrm{~min}$.

$\S$ Compared with group 1.
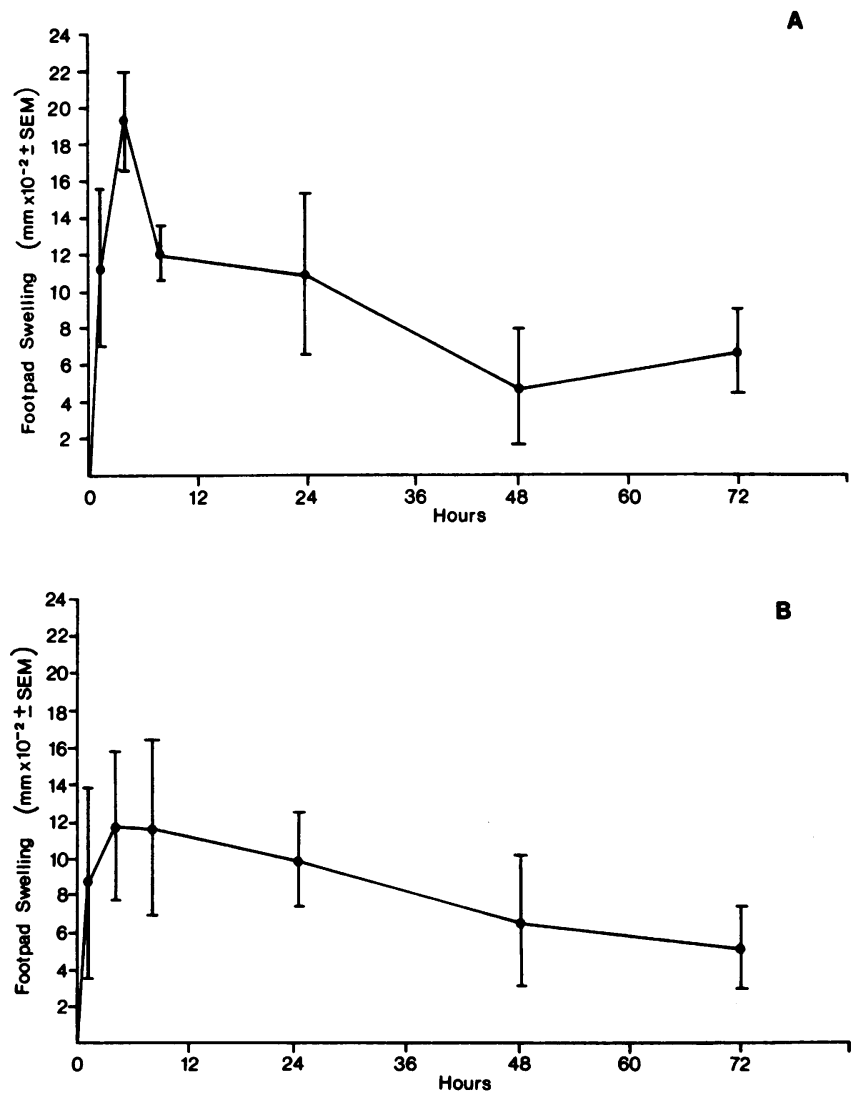

Figure 8. Mice were injected with $0.05 \mathrm{ml}$ of medium containing ETAF in the left hind footpad and medium alone in the right hind footpad. The footpad thicknesses were assessed at the times indicated and the differences between the ETAF and medium-injected footpads plotted. (A) C3H/HeJ mice. (B) A/J mice. 
Table IV. Inflammatory Activity of Endotoxin

\begin{tabular}{lll}
\hline Injection group* & Neutrophils/mm ${ }^{2} \pm$ SEM & $P$ value \\
\hline Endotoxin & $61.2 \pm 18$ & - \\
Medium & $29.8 \pm 18$ & NS $\ddagger$ \\
\hline
\end{tabular}

* Three $\mathrm{C} 3 \mathrm{H} / \mathrm{HeJ}$ mice were injected with $0.05 \mathrm{ml}$ of a $20 \mathrm{ng} / \mathrm{ml}$ solution of $E$. coli lipopolysaccharide or medium in the left hind footpad. Mice were killed $4 \mathrm{~h}$ later and tissue processed.

$¥$ Compared with group 1 .

tween muscle bundles of the panniculus carnosus as well as focal muscle necrosis. Fig. $10 \mathrm{~A}$ shows many of these changes compared with the control, Fig. $10 B$.

\section{Discussion}

In assigning a physiological role to a function defined in vitro, it is essential to demonstrate that the same phenomenon can be produced in vivo. This study demonstrates that ETAF and IL-1 have highly significant activity for the recruitment of neutrophils in vivo. In addition, we have noted that these substances also produce an increase in tissue edema that parallels the time
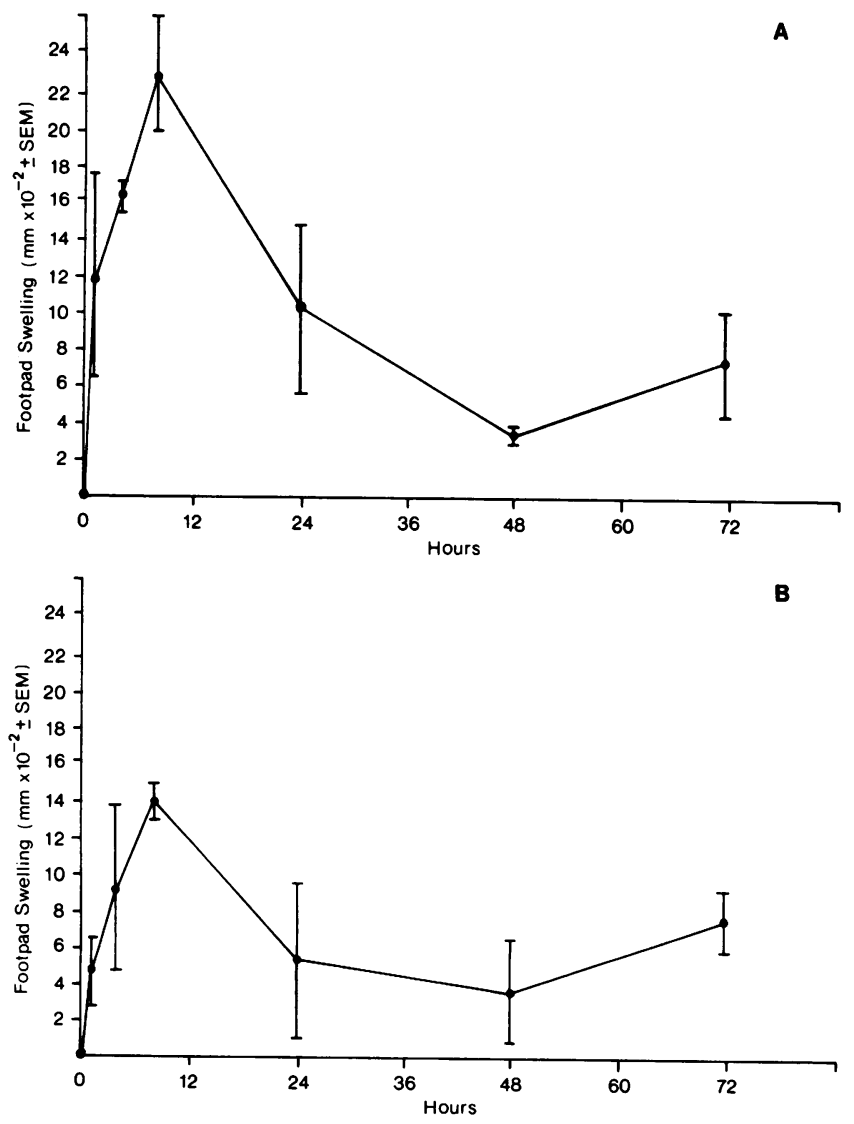

Figure 9. Mice were injected with $0.05 \mathrm{ml}$ of medium containing IL-1 in the left hind footpad and medium alone in the right hind footpad. The footpad thicknesses were assessed at the times indicated and the differences between the IL-1 and medium-injected footpads plotted. $(A) \mathrm{C} 3 \mathrm{H} / \mathrm{HeJ}$ mice; $(B) \mathrm{A} / \mathrm{J}$ mice.
Table V. Inflammatory Activity of Control Proteins

\begin{tabular}{llcl}
\hline Injection group* & Concentration & $\begin{array}{c}\text { Neutrophils/ } \\
\mathrm{mm}^{2} \pm \text { SEM }\end{array}$ & $P$ value \\
\hline Polyhydroxyproline & $\mu g / m l$ & & \\
Medium & 4 & $110 \pm 31$ & - \\
Cytochrome $c$ & - & $33 \pm 10$ & $\mathrm{NS} \ddagger$ \\
Medium & 4 & $51 \pm 15$ & - \\
Human serum albumin & 4 & $56 \pm 43$ & $\mathrm{NS} \S$ \\
Medium & - & $190 \pm 94$ & - \\
Activated serum & - & $102 \pm 33$ & $\mathrm{NS}$ \\
Medium & - & $2,493 \pm 664$ & - \\
& & $33.2 \pm 24$ & $<0.0219$
\end{tabular}

* Three $\mathrm{C} 3 \mathrm{H} / \mathrm{HeJ}$ mice were injected in the left hind footpad with $0.05 \mathrm{ml}$ of Hanks' balanced salt solution containing the indicated substance, and medium alone in the right hind footpad. Mice were killed $4 \mathrm{~h}$ later and tissue processed.

$¥$ Compared with group 1 .

$\S$ Compared with group 3.

"Compared with group 5.

I Compared with group 7.

course for neutrophil accumulation. The finding of tissue edema may be due to a direct effect of ETAF/IL-1, or it may be a secondary effect. In this regard, it is interesting that leukocyte pyrogen (similar or identical to IL-1) has been shown to induce the release of specific granule contents from neutrophils (9). These findings greatly strengthen the evidence that ETAF/IL-1 are important mediators involved in the pathogenesis of acute inflammation. While we cannot be certain that a portion of the inflammatory activity observed is not due to secondary messengers induced by ETAF/IL-1, C5a could not be such a secondary messenger since full inflammatory activity is seen in $\mathrm{A} / \mathrm{J}$ mice, which are known to be C5-deficient (26). This deficiency may, however, account for the lesser footpad swelling seen in $\mathrm{A} / \mathrm{J}$ mice compared with $\mathrm{C} 3 \mathrm{H} / \mathrm{HeJ}$ mice. The specificity of these findings is evident from the inactivity of other proteins at concentrations 2-20 times greater than that of ETAF and IL-1 used in this study. Relatively vigorous heat treatment of ETAF substantially, but not completely, reduces its inflammatory activity while it completely abrogates activity in the thymocyte costimulator assay. However, the inflammatory activity of recombinant IL-1 was abrogated by heating. These observations suggest that the ETAF preparation may indeed contain other heat-stable chemotactic factors unrelated to ETAF. Endotoxin contamination as a possible factor in the results seen with ETAF is excluded because injection of the mouse footpad with more than 10 times the amount present in the preparation failed to show significant activity. Furthermore, treatment of the ETAF preparation with soluble polymyxin $B(500 \mathrm{U} / \mathrm{ml}$ for $30 \mathrm{~min}$ followed by dialysis) did not affect the activity of the preparation (data not shown). Inactivation of the recombinant IL-1 preparation was easily and reproducibly achieved by heat treatment, thus excluding the possibility of significant contamination by heatstable inflammatory factors. Studies will be undertaken in the future with recombinant ETAF derived from human keratinocytes to assess whether a heat-stable chemotactic factor is present in these preparations.

Skin sites injected daily for 5-10 d with ETAF had, in addition to a neutrophilic inflammation, a mononuclear infiltrate, 

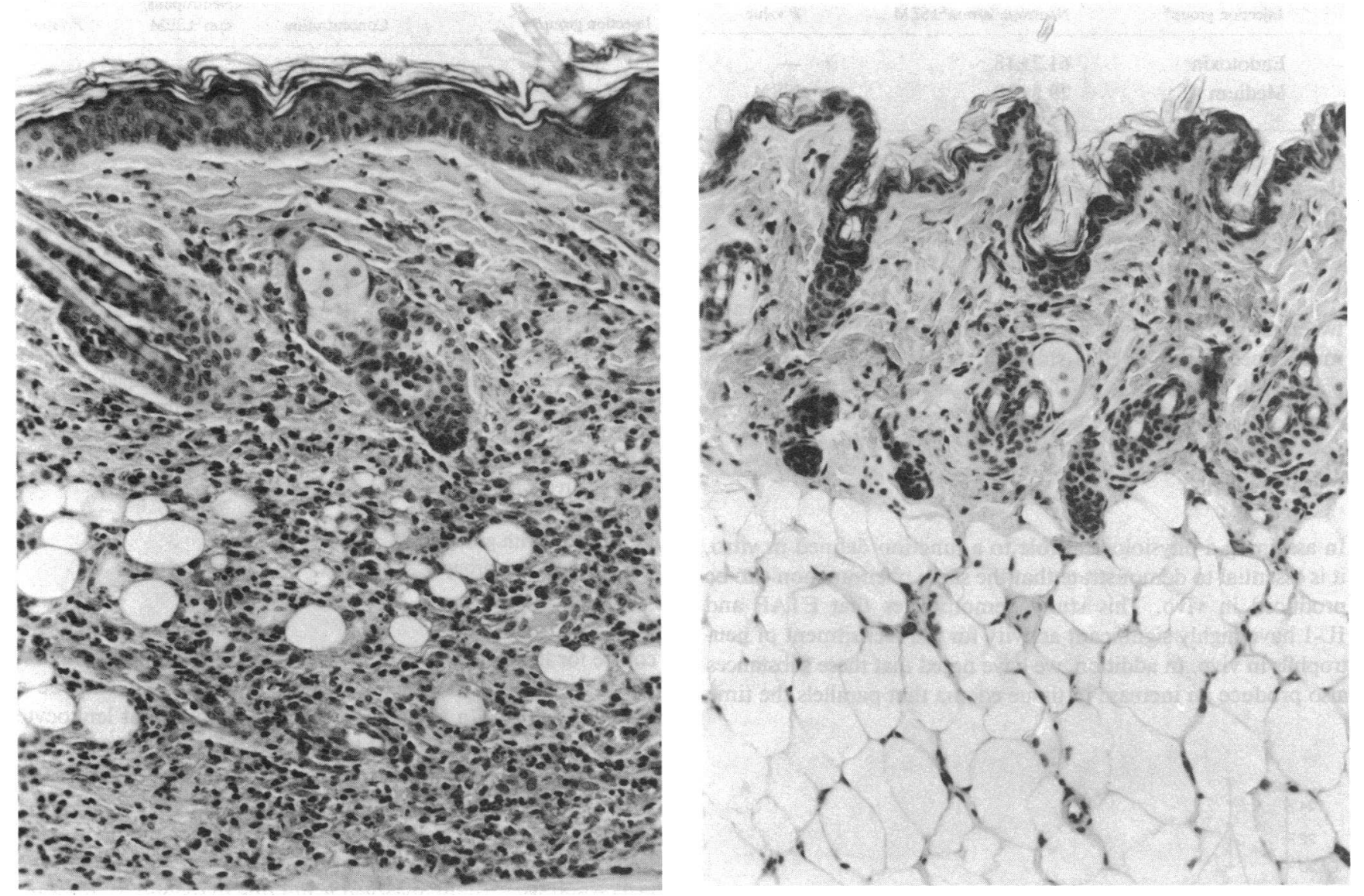

Figure 10. Tissue sections, stained with hematoxylin and eosin, of flank skin injected with ETAF daily for $10 \mathrm{~d}(A)$ or medium $(B), \times 160$. Note epidermal thickening and cellular infiltrate of the ETAF section compared with the control section.

focal muscle degradation, and evidence of fibrosis. While it would be tempting to attribute these findings directly to ETAF, differentiation of primary from secondary (or tertiary) effects are impossible in this type of experiment.

A wide variety of inflammatory and malignant processes in skin and other tissues are characterized in part by infiltration with neutrophils. It is likely that ETAF/IL-1 provides one of the signals for this infiltration. As mentioned above, the sequence of events seen histologically after injection of ETAF or IL-1 (margination of neutrophils within vessels, followed by entry into tissue stroma) suggests that chemotactic activity rather than merely inhibition of migration is being observed. In some experiments utilizing a single injection of ETAF in $\mathrm{C} 3 \mathrm{H} / \mathrm{HeJ}$ mice, an accumulation of mononuclear cells was detected in our assay. This was not seen with purified recombinant IL-1 or in $A / J$ mice. The differences seen in this regard may relate to differences in concentration of the preparations, species differences (ETAF used in this study was of human origin while the IL-1 employed is murine), differences between ETAF and IL-1, or perhaps some contamination of the ETAF preparation with other cytokines.

In addition to demonstrating the inflammatory and probable chemotactic activity of these cytokines in vivo, the assay described in this study may serve as an additional, well-defined model for the study of acute inflammation.

\section{Acknowledgments}

The authors gratefully acknowledge the expert technical assistance of Ms. Claudia Goulston.

This work was supported by National Institutes of Health Clinical Investigator Award AM01425-01 to Dr. Granstein, National Science Foundation grant PCM-8410202 to Dr. Mizel, National Institutes of Health grant AG/AM04956-01 and a grant from the Medical Research Council to Dr. Sauder, and a grant from the Arthur O. and Gullan M. Wellman Foundation.

\section{References}

1. Oppenheim, J. J., B. M. Stadler, R. P. Siraganian, M. Mage, and B. Mathieson. 1982. Lymphokines: their role in lymphocyte response. Fed. Proc. 41:257-262.

2. Smith, K. A., L. B. Lachman, J. J. Oppenheim, and M. F. Favata. 1980. The functional relationship of the interleukins. J. Exp. Med. 151: 1551-1556.

3. Kaye, J., S. Gillis, S. B. Mizel, E. M. Shevach, T. R. Malek, C. A. Dinarello, L. B. Lachman, and C. A. Janeway. 1984. Growth of a cloned helper $\mathrm{T}$ cell line induced by a monoclonal antibody specific for the antigen receptor: interleukin 1 is required for the expression of receptors for interleukin 2. J. Immunol. 133:1339-1345.

4. Dempsey, R. A., C. A. Dinarello, J. W. Mier, L. J. Rosenwasser, 
M. Allegretta, T. E. Brown, and D. R. Parkinson. 1982. The differential effects of human leukocyte pyrogen/lymphocyte activating factor, $T$ cell growth factor, and interferon on human natural killer activity. J. Immunol. 129:2504-2510.

5. Lipsky, P. E., P. A. Thompson, L. J. Rosenwasser, and C. A. Dinarello. 1983. The role of interleukin 1 in human B cell activation: inhibition of $B$ cell proliferation and the generation of immunoglobulin secreting cells by an antibody against human leukocytic pyrogen. J. Immunol. 130:2708-2714.

6. Falkoff, R. J. M., A. Muraguchi, J.-X. Hong, J. L. Butler, C. A. Dinarello, and A. S. Fauci. 1983. The effects of interleukin 1 in human B cell activation and proliferation. J. Immunol. 131:801-805.

7. Dinarello, C. A., and S. M. Wolff. 1982. Molecular basis of fever in humans. Am. J. Med. 72:799-819.

8. Dinarello, C. A. 1984. Interleukin-1 and the pathogenesis of the acute-phase response. $N$. Engl. J. Med. 311:1413-1418.

9. Klempner, M. S., C. A. Dinarello, and J. I. Gallin. 1978. Human leukocyte pyrogen induces release of specific granule contents from human neutrophils. J. Clin. Invest. 61:1330-1336.

10. Sztein, M. B., T. A. Luger, and J. J. Oppenheim. 1982. An epidermal cell-derived cytokine triggers the in vivo synthesis of serum amyloid A Ly hepatocytes. J. Immunol. 129:87-90.

11. Pepys, M. B., and M. L. Baltz. 1983. Acute phase proteins with special reference to $\mathrm{C}$-reactive protein and related proteins (pentaxins) and serum amyloid A protein. Adv. Immunol. 34:141-212.

12. Baracos, V., H. P. Rodemann, C. A. Dinarello, and A. L. Goldberg. 1983. Stimulation of muscle protein degradation and prostaglandin $\mathrm{E}_{2}$ release by leukocytic pyrogen (interleukin-1): a mechanism for the increased degradation of muscle proteins during fever. N. Engl. J. Med. 308:553-558.

13. Postlethwaite, A. E., L. B. Lachman, and A. H. Kang. 1984. Induction of fibroblast proliferation by interleukin-1 derived from human monocytic leukemia cells. Arthritis Rheum. 27:995-1001.

14. Krueger, J. M., J. Walter, C. A. Dinarello, S. M. Wolff, and L. Chedid. 1984. Sleep-promoting effects of endogenous pyrogen (interleukin-1). Am. J. Physiol. 246:R994-999.

15. Luger, T. A., B. M. Stadler, S. I. Katz, and J. J. Oppenheim.
1981. Epidermal cell (keratinocyte)-derived thymocyte-activating factor (ETAF). J. Immunol. 127:1493-1498.

16. Sauder, D. N., C. S. Carter, S. I. Katz, and J. J. Oppenheim. 1982. Epidermal cell production of thymocyte activating factor (ETAF). J. Invest. Dermatol. 79:34-39.

17. Sauder, D. N. 1984. Epidermal cytokines: properties of epidermal cell thymocyte-activating factor (ETAF). Lymphokine Res. 3:145-151.

18. Luger, T. A., B. M. Stadler, B. M. Luger, M. B. Sztein, J. A. Schmidt, P. Hawley-Nelson, G. Grabner, and J. J. Oppenheim. 1983. Characteristics of an epidermal cell thymocyte-activating factor (ETAF) produced by human epidermal cells and a human squamous cell carcinoma cell line. J. Invest. Dermatol. 81:187-193.

19. Luger, T. A., J. A. Charon, M. Colot, M. Micksche, and J. J. Oppenheim. 1983. Chemotactic properties of partially purified human epidermal cell-derived thymocyte-activating factor (ETAF) for polymorphonuclear and mononuclear cells. J. Immunol. 131:816-820.

20. Sauder, D. N., N. L. Mounessa, S. I. Katz, C. A. Dinarello, and J. I. Gallin. 1984. Chemotactic cytokines: the role of leukocytic pyrogen and epidermal cell thymocyte-activating factor in neutrophil chemotaxis. J. Immunol. 132:828-832.

21. Miossec, P., C. L. Yu, and M. Ziff. 1984. Lymphocyte chemotactic activity of human interleukin 1. J. Immunol. 133:2007-2011.

22. Sauder, D. N., C. A. Dinarello, and V. B. Morhenn. 1984. Langerhans cell production of Interleukin-1. J. Invest. Dermatol. 82:605607.

23. Lomedico, P. T., U. Gubler, C. P. Hellmann, M. Dukovich, J. G. Giri, Y. E. Pan, K. Collier, R. Semionow, A. O. Chua, and S. B. Mizel. 1984. Cloning and expression of murine interleukin-1 DNA in Escherichia coli. Nature (Lond.). 312:458-462.

24. Mizel, S. B., and D. Mizel. 1981. Purification to apparent homogeneity of murine interleukin-1. J. Immunol. 126:834-837.

25. Levin, J., P. A. Tomasulo, and R. S. Oser. 1970. Detection of endotoxin in human blood and demonstration of an inhibitor. J. Lab. Clin. Med. 75:903-911.

26. Gervais, F., M. Stevenson, and E. Skamene. 1984. Genetic control of resistance to Listeria monocytogenes: regulation of leukocyte inflammatory responses by the HC locus. J. Immunol. 132:2078-2083. 